\title{
Therapeutic Innovations for Targeting Hepatoblastoma
}

\author{
AGNÈS GARNIER $^{1}$, MATTHIAS ILMER ${ }^{2}$, ROLAND KAPPLER ${ }^{1}$ and MICHAEL BERGER ${ }^{1,3}$ \\ ${ }^{1}$ Department of Pediatric Surgery, Research Laboratories, Dr. von Hauner Children's Hospital, \\ Ludwig Maximilians University Munich, Munich, Germany; \\ ${ }^{2}$ Department of General, Visceral, and Transplantation Surgery, Hospital of the LMU, Munich, Germany; \\ ${ }^{3}$ Department of Transplant Surgery, Emory University, Atlanta, GA, U.S.A.
}

\begin{abstract}
Hepatoblastoma is the most common pediatric liver tumor. Despite recent advances in treatment with surgery and chemotherapy, the prognosis in advanced stages remains poor. The neurokinin-1 receptor (NK1R) has recently been described to be pivotal in the development of cancer. Furthermore, overwhelming evidence now exists showing that pharmacological manipulation of NKIR can cause a robust anticancer effect. Consequently, NKIR antagonists, such as the clinical drug aprepitant, are under current investigation as future innovative anticancer agents. In that sense, new evidence suggests that NKIR is highly expressed in human hepatoblastoma and can be targeted to create a robust inhibiton of tumor growth in vivo and in vitro. The mechanisms behind this effect are only now being investigated but already reveal an arsenal of therapeutic possibilities. Our article describes the most recent developments in the field of therapeutic NKIR inhibition in cancer and focuses particularly on the newly discovered molecular mechanisms involved when targeting NKIR in hepatoblastoma.
\end{abstract}

Despite being a rare childhood cancer that accounts for only $1 \%$ of all pediatric neoplasms, hepatoblastoma represents $80 \%$ of hepatic-related cancers in children. It affects approximatively 1:1,000,000 children under the age of 15 and most predominantly between 6 months and 3 years $(1,2)$. It has been reported that the risk of developing hepatoblastoma is increased in subjects that are afflicted by several syndromes, such as Beckwith-Wiedemann syndrome (BWS)

This article is freely accessible online.

Correspondence to: Michael Berger, MD, Ph.D., Department of Pediatric Surgery, Dr. von Hauner Children's Hospital, Ludwig Maximilians University Munich, Lindwurmstrasse 4, 80337 Munich, Germany. Tel: +49 89440057811, Fax: +49 89440057815, e-mail: michael.fabian.berger@gmail.com

Key Words: Hepatoblastoma, NK1R, childhood cancer, review.
(3), hemihypertrophy or familial adenomatosis polyposis (FAP) (4). Previous studies have also reported an increased incidence in subjects with low birth weight (5).

Hepatoblastoma is most frequently detected by palpation of an asymptomatic hepatomegaly. Other clinical presentations can include jaundice, weight loss, pain and/or fatigue depending on how far the tumor has progressed. Blood tests often reveal high levels of alpha-fetoprotein (AFP), a robust marker of hepatoblastoma (6). Imaging, such as computed tomography (CT) scan and magnetic resonance imaging (MRI) are key for diagnosis and, typically, show an ill-defined, invasive mass in the liver parenchyma. Hepatoblastomas can be either unifocal or multifocal, with the latter having a worse prognosis. Synchronous metastases are present in $20 \%$ of hepatoblastomas and are often localized in the lung, whereas metachronous metastases are generally found in the lung as well as the brain and bones (7).

The etiology of hepatoblastoma is still not known; however, tumorigenesis is believed to occur through a derailed development of immature hepatocyte precursors, which normally differentiate into several cell types, including hepatocytes, epithelial, biliary and mesenchymal cells. This explains the cellular heterogeneity of the tumor and the different histological subtypes observed. Hepatoblastoma can be classified into epithelial (56\%) or mixed forms (epithelial and mesenchymal, 44\%). The epithelial form further regroups into pure fetal (31\%), embryonal (19\%), macrotrabecular (3\%) and small-cell undifferentiated (3\%) subtypes (8), with the latter being associated with poor prognosis (9).

There are currently four leading childhood liver study groups in the world: the International Society of Pediatric Oncology group (SIOPEL), which is located in Europe, the Children's Oncology Group (COG) in North America and the national study groups from Germany (GPOH) and Japan (JPLT). As mentioned above, techniques, such as MRI, CT and blood tests are used to evaluate the PRE-Treatment tumor EXTension (PRETEXT), POST-Treatment EXTent of Tumor (POSTTEXT), AFP level, tumor histology and metastatic diseases (10-13). Each group has their own 
staging system and treatment strategies, although recent efforts are made toward standardization (14). Here, we will only describe the methodologies instigated by the SIOPEL and COG groups.

The PRETEXT staging system, originally created by the SIOPEL group, is based on imaging prior to any treatment to characterize the localization of the tumor using Couinaud's system of segmentation of the liver. It distinguishes four PRETEXT stages but also uses other parameters to assess the spread of the tumor beyond the liver (lymph node metastases, portal vein involvement, involvement of the inferior vena cava and/or hepatic veins, extrahepatic abdominal disease, tumor rupture or intraperitoneal haemorrhage disease, distant metastases) (15). On the other hand, the POSTTEXT staging system was developed by the COG group. The staging methodology consists of an initial surgery attempt to completely resect the tumor followed by chemotherapy courses. Following surgery, four groups are distinguished depending on the stage: stage I corresponds to complete resection; stage II to microscopic residual; stage III to macroscopic residual and stage IV to distant metastases.

\section{Molecular Alterations in Hepatoblastoma}

Different molecular alterations have been identified as being involved in the genesis of hepatoblastoma. Particularly, a deregulation of different signaling pathways has been described among which the canonical Wnt signaling, Sonic Hedgehog, Notch and phosphatidylinositol 3-kinase/protein kinase $\mathrm{B} / \mathrm{mammalian}$ target of rapamycin (PI3K/AKT/ mTOR) are counted as the main players (16).

\section{The Canonical Wnt Signaling Pathway}

The canonical Wnt signaling pathway is known to play a vital role in the regulation of cell proliferation, survival and differentiation (17). Particularly, this pathway is important in liver homeostasis: from embryonic liver to its functional maturation, which reinforces its role in hepatoblastoma tumorigenesis (18-20). In the adult liver, canonical Wnt signaling is only activated in the centrizonal region of the hepatic lobule as proven by positive nuclear and cytoplasmic $\beta$-catenin in this area $(20,21)$. It is known to regulate genes involved in ammonia and xenobiotic metabolism (22). On the other hand, Wnt signaling can be reactivated during liver regeneration in adults (23). This unique process allows for spontaneous regrowth of the liver parenchyma after partial hepatectomy (24). This phenomenon occurs through the proliferation of mature cells, including hepatocytes, without causing any inflammation to the surrounding tissues (25). At the molecular level, Wnt signaling is quickly activated through inhibition of $\beta$-catenin degradation resulting in an increase of the protein by 2.5 -fold and, therefore, its subsequent nuclear translocation (23). In the nucleus, $\beta$-catenin induces proliferation through the regulation of several genes such as CCNDI (20) and its protein level returns back to normal 48 hours post resection (23).

Dysfunction of this pathway is implicated in several diseases, including benign and malignant tumors. Typically, alterations at different levels of the pathway can lead to aberrant enhanced presence of $\beta$-catenin in the cytosol. In most cases, however, the $\mathrm{N}$-terminal fragment of $\beta$-catenin is being deleted or altered, which consequently protects it from degradation (26). Therefore, excess $\beta$-catenin translocates to the nucleus where it binds to transcription factors lymphoid enhancer factor/T-cell factor (LEF/TCF), resulting in the overexpression of Wnt target genes. Mutations of the $\beta$-catenin gene CTNNB1 are found in numerous cancers, including colorectal, hepatocellular, ovarian cancers and, notably, hepatoblastoma (26). More particularly, high frequency of point mutations and deletions in exon 3 of $C T N N B 1$ was first reported by Koch et al. (27) and confirmed by others (49\%-89\%) (28) indicating a crucial role of this pathway in hepatoblastoma. Subsequent immunohistochemistry experiments confirmed an aberrant cytoplasmic/nuclear localization of $\beta$-catenin in the majority of hepatoblastomas (29-31). Other members of the pathway have also been screened for mutations in sporadic hepatoblastoma, such as $A X I N 1, A X I N 2$ or $A P C$. Although some discrepancies exist between studies, $A X I N 1$ was found mutated in $1.6 \%$ (32) or $7.4 \%$ (33), whereas AXIN2 was found mutated in $5.4 \%$ (34) of the cases investigated. Furthermore, germline mutations of $A P C$ were reported in $10 \%$ (35) and somatic mutations in $61.5 \%$ (36) of sporadic hepatoblastoma. Apart from this, one study focusing on Wnt antagonists revealed a transcriptional up-regulation of this particular class in hepatoblastoma cells. The fact that Wnt signaling is constitutively expressed in Wnt-mutated cells, despite the high level of antagonists, indicates the presence of a complex regulation mechanism of $\beta$-catenin within these cells (37).

Many Wnt target genes have been discovered among which the proto-oncogene $M Y C$, the cell cycle regulator CCND1 (38) or the intestinal stem cell marker LGR5 (39) play pivotal roles in different neoplasms. In hepatoblastoma, however, previous studies have found no correlation between elevated Wnt activity and $M Y C$ expression in normal liver cells or hepatoblastoma cells, which implies that this gene is most likely not a Wnt target gene in this context $(30,40,41)$. Furthermore, converging studies showed that Wnt target genes are cell- and context-specific (42). Other target genes include actual components of the Wnt pathway (Frizzled, LRP5/6, AXIN, LEF/TCF) providing a mechanism by which this pathway could auto-regulate itself (43). 


\section{PI3K/AKT/mTOR Axis}

The PI3K/AKT/mTOR signaling pathway is involved in the regulation of many cellular functions, such as metabolism, proliferation, survival and motility (44). This pathway is often deregulated in cancer cells (45) as most of its proteins are tumor suppressor genes or proto-oncogenes whose mutation or anarchic expression can promote the development of a tumor $(46,47)$.

The PI3K/AKT/mTOR pathway is most often activated through a receptor tyrosin kinase (RTK), itself stimulated by multiple ligands (growth factors, such as insulin-like growth factor (IGF), epidermal growth factor (EGF) or cytokines). It induces the activation of many intracellular proteins through cascades of phosphorylations (48). A study conducted by Hartmann et al. (45) revealed that point mutation of the effector PI3KCA (p110 $\alpha$ subunit of PI3K) was present in $2 \%$ of hepatoblastomas resulting in a gain of kinase activity. Moreover, they found that PI3K/AKT/mTOR activation was actually central for hepatoblastoma survival as demonstrated by PI3K inhibition in vitro and subsequent reduction of AKT and GSK3 $\beta$ phosphorylation (45). Further, the IGF axis was also shown to be implicated in hepatoblastoma growth (49). This pathway was found to be overactivated as a result of IGF2 ligand overexpression, confering a constant anti-apoptotic signal to the cells mediated through the insulin-like growth factor 1 receptor (IGF1R) (50). IGF2 expression is normally restricted to the paternel allele as the maternal copy is epigenetically silenced, a phenomenon called genomic imprinting. In hepatoblastoma, however, loss of imprinting was described for $I G F 2$ and is responsible for an abnormal biallelic expression (51). Finally, regulators of the latter axis have also been implicated in hepatoblastoma growth, namely the insulin-like growth factor binding proteins (IGFBP). These repressors bind to ligands by physical interaction in order to prevent their interface with the receptor. Interestingly, IGF2 and $I G F B P 2$ expression levels were found to be inversely correlated with the degree of cell differentiation indicating that IGFBP2 expression could be used as a marker of differentiation in hepatoblastoma (52). Furthermore, a study conducted by Regel et al. revealed high levels of DNA methylation in the IGFBP3 promoter region in hepatoblastoma cell lines but also primary tumors. The authors could link this epigenetic alteration with the loss of protein expression and correlate it with vascular invasion and metastatic tumors (53).

\section{Other Molecular Alterations Described in Hepatoblastoma}

In order to understand the etiology of hepatoblastoma as a pediatric cancer, studies have also focused on two other embryonic pathways, namely Hedgehog and Notch. In particular, one study reported an overexpression of hedgehog members GLII and PTCHI in tumors compared to normal liver tissues (54). More impressively, inhibiting this pathway with cyclopamine induced a striking growth inhibition of hepatoblastoma cells (54). On the other hand, when analysing Notch signaling by immunohistochemistry, Litten et al. revealed an overexpression of the $\mathrm{NOTCH} 2$ receptor in $92 \%$ of the tumors compared to normal liver tissues (55). This result corroborates the idea that hepatoblastoma arises from immature precursors as $\mathrm{NOTCH} 2$ is known to repress hepatoblast differentiation during embryogenesis and sees its expression decrease with liver maturation (56).

The field of epigenetics has been at the forefront of cancer research during the last few years due to the emerging evidence of its involvement in pathological cell processes. In hepatoblastoma, several tumor suppressor genes have been reported to be altered through DNA methylation in their promoter sequence, which in turn inactivates them. For instance, secreted frizzled-related proteins (SFRP) or Hedgehog-interacting proteins (HHIP), which antagonize the Wnt and Hedgehog pathway, respectively, are altered through hypermethylation (54). Therefore, loss or decrease of expression results in enhanced activity of the pathway and, potentially, contributes to the tumorigenesis process. Finally, $A P C$ silencing through hypermethylation has been described in about $30 \%$ of hepatoblastoma and is responsible for excess cytosolic $\beta$-catenin as the destruction complex is impaired (57).

Apart from this, genetic aberrations in several chromosomes have been identified, such as gains of chromosomes 1q, 2q, 2p, 6q, 8q, 17q and 20 and losses on chromosomal region $4 \mathrm{q}$ (58). Interestingly, gains on chromosomes 8 and 2 were found to be associated with a purported C2 subclass of hepatoblastoma introduced by Cairo et al. (32). Using gene expression profiling, this group identified two subclasses of hepatoblastoma tumors, namely $\mathrm{C} 1$ and $\mathrm{C} 2$, which exhibit similarity with distinct phases of liver development. The C2 subclass, which conforms to an embryonal histotype, was found to proliferate faster than the fetal-like $\mathrm{C} 1$ subclass. In accordance, the $\mathrm{C} 2$ tumors highly expressed cell cyclerelated genes such as $C D C 2$ and $D L G 7$ and displayed intense nuclear accumulation of $\beta$-catenin. Importantly, they described a 16-gene signature, which corresponds to the 16 most differentially expressed genes between $\mathrm{C} 1$ and $\mathrm{C} 2$ and, therefore, allows classification of the tumors between these two subclasses (32). From a clinical perspective, the tumors with a $\mathrm{C} 2$ signature were shown to be associated with poor prognosis for the disease with a more advanced tumor stage (metastasis, vascular invasion). The 2-year overall survival was $44 \%$ for patients with C2 tumors against $92 \%$ for patients with $\mathrm{C} 1$ tumors (32). 


\section{Conventional Treatment Strategies}

During the last 30 years, several clinical trials have been conducted to increase the survival of children with hepatoblastoma. One of the major breakthroughs is the use of platinum-based chemotherapeutic agents (such as cisplatin and carboplatin), which greatly improved the survival in children from $30 \%$ to $70 \%$ (2).

Cisplatin alone (59) or in combination with other cytostatics (5-fluorouracil, vincristine, doxorubicin, carboplatin) remains the first choice for chemotherapy courses in all four liver study groups. The chemotherapy recommendations depend on the stage of the tumor and differ between the four liver study groups $(60,61)$, although all four groups recently adopted the PRETEXT staging system (62). For instance, SIOPEL recommends preoperative chemotherapy with the ultimate goal to shrink the tumor to allow tumor resection, which is one way to achieve a definitive cure (63). In some cases, such as in patients with a pure fetal histology tumor, chemotherapy is not advised and only surgery is advocated as being curative by itself (64). On the contrary, in children with unresectable tumors, upfront but not rescue (after failed resection) orthotopic liver transplantation is the main choice for treatment $(65,66)$.

Despite the advances witnessed in hepatoblastoma treatment evoked above, there remains a large margin for progress, both in terms of the effectiveness of the treatments and severity of their side-effects. For instance, high-risk patients (SIOPEL PRETEXT IV or COG stage IV) have a 5year overall survival rate in between $30.9 \%$ and $39.3 \%$ depending on the staging system (67). Furthermore, one limitation of chemotherapy treatment is multidrug resistance (MDR), which often occurs after four cycles of chemotherapy (67). It is, for example, associated with an increased expression of the MDR gene coding for P-glycoprotein (68), an ATP-reliant pump allowing the evacuation of drugs or other molecules (69). Another downside with the use of chemotherapeutic agents is the strong toxicity induced by these molecules. Cisplatin is responsible for ototoxicity and nephrotoxicity after several courses (70), whereas doxorubicin is higly cardiotoxic (71).

\section{The Substance P/Neurokinin-1 Receptor}

The neurokinin receptors regulate a variety of fundamental biological processes, including the regulation of neuronal activity, cell proliferation, nociception, endocrine and exocrine secretions, vasodilatation, inflammation and regulation of the immune system (72-75).

Currently, there are three main classes of neurokinin receptors characterized in humans: neurokinin-1 receptor (NK1R), neurokinin-2 receptor (NK2R) and neurokinin-3 receptor (NK3R), which are encoded by TACR1, TACR2 and
TACR 3 genes, respectively. The ligands of these receptors belong to the tachykinin family and each ligand has a specific affinity for one of the three receptors. For instance, neurokinin A binds preferentially to NK2R, neurokinin B to NK3R and Substance P (SP) to NK1R (72). Neurokinin receptors, which are G-protein coupled receptors (GPCRs), have high sequence and structure homologies but are differentially expressed within human tissues. NK1R is expressed in the central nervous system, as well as in the periphery, while NK2R is mainly expressed in peripheral tissues, such as the gastrointestinal system, lungs, bladder and the uterus. NK3R is found in the central nervous system but its expression is also detected in some peripheral tissues, such as the liver and lungs (72, 76-79).

In humans, the TACRI gene is located on chromosome 2 and is constituted of five exons. In its full-length form, NK1R is a protein of 417 amino acids (80). It belongs to the class I of GPCRs and can be coupled to several groups of $\mathrm{G}$

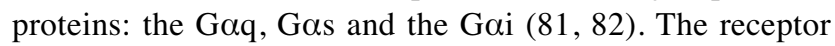
conformation and the types of ligands have been shown to determine the specificity of the response through the activation of a specific $G$ protein $(83,84)$. Indeed, these proteins differ in their signaling pathway and effectors that they activate. For example, the coupling with the Gaq protein results in the activation of phospholipase $C \beta$ (PLC $\beta$ ), which causes an increase of PIP3. The activation of PLC $\beta$ also induces the release of diacylglycerol (DAG), which ultimately induces an increase of intracellular calcium (85).

The coupling with Gas activates the enzyme adenylate cyclase (AC) and, thus, stimulates the production of cyclic adenosine monophosphate (cAMP). An increased concentration of cAMP activates the protein kinase A (PKA), which phosphorylates specific substrates (86). Finally, coupling with Gai inhibits AC, which, thereafter, decreases the concentration of cAMP in the cell $(87,88)$. In any case and most importantly, these cascades lead to an exclusive physiological response via the transcription of specific genes.

The NK1R, like other GPCRs, undergoes a rapid desensitization and internalization through phosphorylation processes with a subsequent recycling to the membrane (89). More precisely, this mechanism is relies on $\beta$-arrestin/clathrin proteins and endocytosis (90). Interestingly, Roosterman et al. showed that NK1R internalization is dependant on the SP concentration: at low concentrations $(1 \mathrm{nM})$ the receptor is internalized and quickly recycled at the membrane, whereas, at high concentrations $(10 \mathrm{nM})$, the process takes more time with an endocytosis into perinuclear endosomes (91).

Recently, the description of a truncated form of the NK1R was reported (NK1R-tr). This isoform is produced by alternative splicing. The intron between exons 4 and 5 is not removed and, therefore, a premature stop codon appears resulting in a protein lacking 96 amino acids at the Cterminus $(92,93)$. Importantly, the loss of this specific part 
was associated with a loss of internalization (94). NK1R-tr expression was detected in specific regions of the brain or the spinal cord and in the central nervous system. It is also abundant in peripheral tissues, such as the prostate, adipose tissue, heart, lungs and spleen. Functional differences between the long (NK1R-fl) and the truncated form of NK1R have been described. Firstly, as mentioned above, NK1R-tr is resistant to desensitization. Secondly and contrary to NK1R$\mathrm{fl}$, the truncated form is able to induce a rapid but sustained calcium response (94). This difference could be explained by a lower affinity of SP for the truncated form and by the absence of a rapid desensitization, which, therefore, promotes a prolonged activity (92).

The first generation of NK1R antagonists was developed from the modification of the SP sequence; however, these peptides were particularly unstable and toxic (95). A breakthrough in the development of NK1R antagonists, achieved by random screening of chemical libraries, was the discovery of non-peptide compounds, such as L-733.138, L733.060 and L-703.606, which showed a great affinity for the NK1R. By improving the pharmacokinetic properties of L733.060 , Merck Frosst developed the molecule MK860 or aprepitant (96). Aprepitant, or its commercial name Emend ${ }^{\circledR}$, is the first NK1R antagonist approved by the Food and Drug Administration (FDA) and Health Canada in 2009 for its antiemetic properties. More precisely, it is used at low doses in triple therapy for the prevention of chemotherapy-induced nausea and vomiting in adults only (97). Previous studies have unveiled other very interesting properties of these antagonists depending on the dose at which they are used. At medium doses, they can treat depression or pain, whereas, at high doses, a potent anticancer effect has been shown (98, 99). Consequently, the use of NK1R antagonists bear enormous potential for future anticancer treatment strategies, knowing that many patients with cancer suffer from symptoms that could potentially be addressed simultanoulsy while causing an anticancer effect.

\section{Therapeutic Innovations in Hepatoblastoma}

\section{The NK1R as a Tumor Target in Hepatoblastoma}

In a recent paper, we were able to describe the SP/NK1R complex as a potentent target in hepatoblastoma (100). We found that this receptor was highly expressed in hepatoblastoma cell lines and its inhibition by small molecules was responsible for a robust inhibition of proliferation with induction of apoptosis in vitro. Additionally, in the HuH6 xenograft tumor mouse model, aprepitant alone significantly reduced tumor growth in vivo (100). In that same paper, we were able to describe that combining aprepitant with cytostatics revealed an additive effect. This was observed with doses as low as $1 \mu \mathrm{M}$ of doxorubicin. In line with these observations, osteosarcoma cell lines showed a similar effect with NK1R antagonists for mitomycin, ifosphamide, adriamycin and cisplatin (99). What is important to point out is that, in either study, results were obtained after single treatments and are not representative of the clinical setting where several chemotherapy courses are needed. It would be interesting to further investigate how combinations of low-dose chemotherapeutic agents with aprepitant affect tumor growth in vivo. Obviously, the ultimate goal would be to decrease the concentration of cytostatics given their potential for severe side-effects, especially when given at high doses. In the treatment of childhood cancer, particularly, doxorubicin is responsible for cardiotoxicity (71), whereas cisplatin causes nephrotoxicity and ototoxicity (8).

Despite being highly expressed in neoplastic cells, the $\mathrm{SP} / \mathrm{NK} 1 \mathrm{R}$ complex has been recently incriminated as an important actor of the tumor microenvironment. For instance, high expression of NK1R in capillaries was recently linked to tumor neovascularization, which participates in the angiogenesis process (101). More precisely, SP, which is highly expressed by the tumor itself but also by other structures, such as peripheral terminal nerves or infiltrating immune cells (77), was shown to induce the growth of capillary vessels in vivo and trigger the proliferation of endothelial cells in vitro. Additionally, SP acts as a proinflammatory compound, which potentially could contribute to tumor-promoted inflammation, a previously described hallmark of cancer (102). The fact that cancer cells produce SP also suggests the presence of an autocrine growth stimulus pattern. Mayordomo et al. used a monoclonal, specific antibody against this agonist in isolated cultures of breast cancer and other cancer cell lines and observed an inhibition of cell growth and an increase of apoptosis (103). Similarly, when using anti-SP or anti-NK1R antibodies, a significant growth inhibition was noted in our study. These findings converge to the fact that hepatoblastoma cells are capable of auto-stimulation, which, therefore, reinforces the preeminence of NK1R as a driver of hepatoblastoma growth.

Nevertheless, there are many unresolved questions concerning the true role of the SP/NK1R system in the development of cancer. For instance, until recently, little attention has been given to the different splice variants of NK1R. Previous studies pointed out the central role of NK1R-tr in breast cancer $(104,105)$. Likewise, Gillespie et al. analyzed NK1R-tr and NK1R-fl in colitis-associated cancer and found that it was the expression of NK1R-tr alone that predicted the progression from quiescent colitis to highgrade dysplasia and cancer (106). Compared to NK1R-fl, the truncated variant is lacking residues at the cytoplasmic end of the receptor. Nonetheless, it seems to be able to couple to $G$ proteins but shows reduced efficiency with respect to internalization and desensitization. The analysis of NK1R 
expression in hepatoblastoma cells revealed an overexpression of the truncated isoform, whereas NK1R-fl was very little expressed. In comparison, human fibroblasts and non-malignant HEK293 cells expressed negligible levels of NK1R-tr. This receptor system seems to be of minor importance in human fibroblasts, since both splice variants were barely detectable. Interestingly, these cells showed the strongest resistance to aprepitant when analyzing cell survival, whereas HEK293 cells, which expressed higher levels of NK1R-fl, displayed an increased response to aprepitant. Taking these results into account, it seems that the response to NK1R antagonists is selective and relies on the differential expression of the receptor within these cells. However, at the moment, the existing evidence does not permit us to establish clearly a causal relationship between the expression level of splice variants and the sensitivity to aprepitant. Nevertheless, as NK1R-tr is believed to be resistant to desensitization and internalization, one could suggest that this isoform is responsible for a constitutive growth stimulus. Therefore, it would be interesting to realize complementary experiments, such as $N K 1 R$-knockdown, to investigate in detail the functional role of this specific isoform in hepatoblastoma development. When addressing this particular question, one significant limitation that we have faced is the tendency that NK1R-deficient cell lines, once a significant knockdown has been successfully accomplished, die off very quickly.

\section{Downstream Mechanisms Following Inhibition of Hepatoblastoma with NK1R Inhibitors}

Until recently, very little was known regarding the exact subcellular signaling mechanisms following the inhibiton of NK1R in the various different cancer cells. Recently, our group was able to describe the downstream mechanisms following inhibition of NK1R by aprepitant on hepatoblastoma cells (107). First, a robust inhibition of 4EBP1 and p70S6K was identified, which are both downstream members of the PI3K/AKT/mTOR pathway. This is promising because this pathway is known to be involved in tumorigenesis and was identified as a potent target for the development of future anticancer strategies (108). In particular, previous work showed that the inhibition of hepatoblastoma cell growth could be achieved with the use of rapamycin through inhibition of the PI3K/AKT/mTOR pathway by dephosphorylating and deactivating p70S6K (109). Furthermore, the inhibition of both p70S6K and 4EBP1, in our study, is in accordance with Mayordomo et al. (103). This group treated breast, prostate and colon cancer cells with SP antibodies, which led to the inhibition of mTOR. Likewise, Garcia-Recio et al. showed that SP induced an activation of the pathway with an early increased expression of p-AKT in breast cancer cells (110). Finally, we were able to confirm, to some extent, an inhibition of this particular pathway in colorectal cancer cells, which followed the same pattern as in hepatoblastoma cells (111).

When analyzing the effect of aprepitant at the molecular level in more detail, we found an unexpected increase of AKT phosphorylation (S473 and T308) suggesting an activation of the PI3K/AKT/mTOR pathway. This was confirmed by an increase of AKT substrate-specific phosphorylation of PRAS40 (T-246)(112) and GSK3 $\beta$ (S9) (113) (Figure 1). However, activation of mTORC1 following aprepitant treatment is questionable for several reasons. Importantly, 4EBP1 was found phosphorylated at T37/T46 and, although it is known that mTORC1 mediates this phosphorylation (114), other kinases have this ability as well. For instance, phosphorylation of 4EBP1 at these two distinct sites can be performed by CDK1 under conditions of reduced mTOR signaling (115). Likewise, PLK1 was shown to have similar effects in HepG2 (116). Furthermore, our data also indicated an increase in phosphorylation of mTOR at S2448, which, in this form, is known to be associated with mTORC1 complex (117) (Figure 1). At first, we speculated that it was an indicator of mTORC1 activity. However, mutation of S2448 to A2448 has no discernible effect on the ability of mTOR to activate its downstream effectors. More interestingly, deletion of this region resulted in enhanced mTOR kinase activity suggesting that this region may actually act as a repressor domain (118). Therefore, the more grounded hypothesis would consider mTORC1 to be inhibited after aprepitant treatment.

Another indicator of mTORC1 inhibition is hyperactivation of mTORC2 as illustrated by increased phosphorylation of AKT at S473 and decreased phosphorylation of Rictor at T1135 (119) (Figure 1). We speculate that inhibition of the mTORC1 complex suppresses the negative feedback of $\mathrm{mTOR} / \mathrm{p} 70 \mathrm{~S} 6 \mathrm{~K}$ activation on insulin receptor substrate 1 (IRS1) (120-122) and Rictor (T1135) (123). In the same manner, Western blots of AKT after short time treatment revealed first a decreased expression of phospho-AKT (S473) followed by a subsequent increase probably due to the loss of these negative feedback loops. Late AKT activation would, therefore, represent a rescue reaction of the tumor cells to escape cell death. This phenomenon was already described after everolimus treatment where the negative feedback via p70S6K on mTORC2 is inhibited allowing AKT phosphorylation at S473 by the mTORC2 complex (124). Importantly, it has been suggested that increased AKT signaling, following mTORC1 inhibition, could attenuate anticancer efficacy over time and contribute to the development of resistance $(124,125)$.

Furthermore, we identified a nuclear localization of phospho-mTOR (S2448) and phospho-AKT (S473) upon aprepitant treatment. mTOR is believed to be cytoplasmic (126); however, our immunofluorescence staining in untreated cells revealed that mTOR was present in the cytoplasm and, 


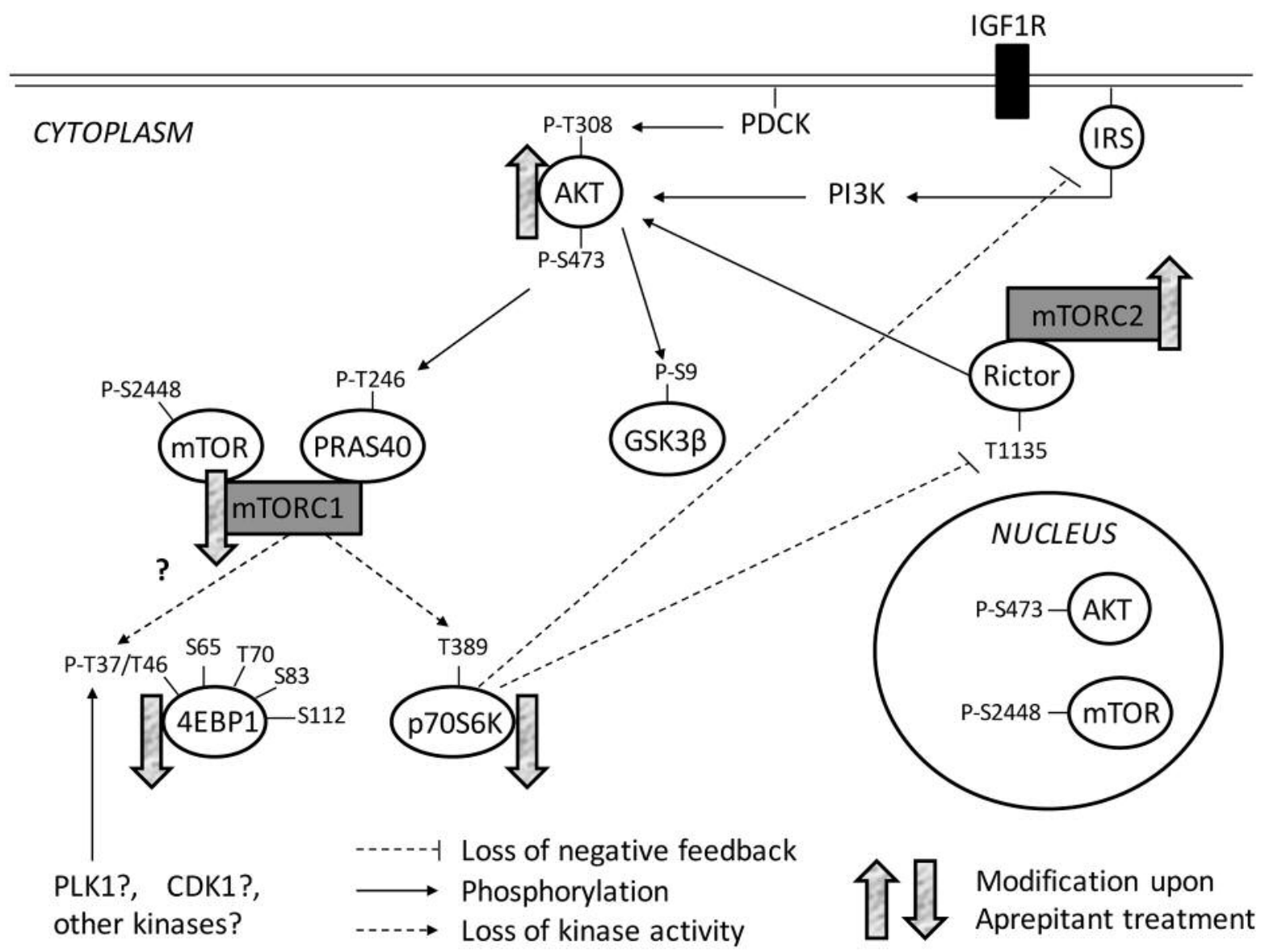

Figure 1. Schematic representation of aprepitant action on PI3K/AKT/mTOR pathway in hepatoblastoma based on RPPA and Western blot data. Following aprepitant treatment, mTORC1 is inhibited as proven by decrease of its downstream targets p70S6K (T389) and 4EBP1 (S65). AKT becomes activated due to the loss of negative feedback of p70S6K on Rictor (decrease of phosphorylation at T1135) and on insulin receptor substrate (IRS) protein. Activated AKT phosphorylates GSK3 $\beta$ (S9) and PRAS40 (T246) and promotes, for instance, cell survival.

to a lesser degree, in the nucleus. Although no classic nuclear localization sequences have been found in mTOR, we think that this particular localization could be explained by the presence of a rapid nuclear export mechanism compared to the nuclear import, which could explain the strong nuclear accumulation of mTOR, AKT and FOXM1. Interestingly, Kim et al. (127) reported the same atypical localization of mTOR. Additionally, they observed an accumulation of nuclear mTOR upon leptomycin B treatment, an inhibitor of CRM1dependent nuclear export, which was associated with a decrease of p70S6K and 4EBP1 phosphorylation. Hence, it is possible that a perfect balance between cytoplasmic and nuclear mTOR is needed for maximal mTOR activity (128). By dysrupting a shuttling mechanism, aprepitant could induce a strong accumulation of mTOR in the nucleus, which, therefore, would inhibit cytoplasmic mTORC1 downstream targets, such as p70S6K and 4EBP1.
Apart from this, increase of nuclear AKT was also detected upon aprepitant treatment. In the nucleus, active AKT can phosphorylate several intracellular substrates to promote cell survival or DNA repair (129). Furthermore, strong nuclear presence of AKT (S473) has been described in several cancer types, which corroborates the potential role of AKT in the development of drug resistance. Importantly, this phenomenon could explain our in vivo data. Despite the fact that aprepitant induced a significant reduction of tumor growth compared to untreated control animals, we observed a slight increase in tumor volume over time growing from 75 to $200 \mathrm{~mm}^{3}$ after 20 days of treatment (100).

Taken together, there is now strong evidence that identifies the PI3K/AKT/mTOR pathway as one major downstream mechanism responsible for NK1R-triggered growth inhibition in hepatoblastoma. However, several efforts have to be made to clearly understand the 
mechanisms involved in the regulation of AKT. For instance, Wan et al. successfully suppressed reactivation of AKT by targeting mTOR but also IGF1R (130). This could lead to the development of new approaches that completely or partially abrogate this pathway pivotal to drug resistance.

\section{Targeting the NK1R Compromises Canonical Wnt Signaling in Hepatoblastoma}

The canonical Wnt pathway and the NK1R signaling complex have traditionally been seen as two independent cancer pathways. In our group, we observed a striking reduction of Wnt activity as confirmed by reduced luciferase activity in SuperTOP/FOP assays and by decrease of Wnt target gene expression. First, this effect seemed to be limited to cells with mutations of the Wnt pathway or cells in which the pathway was extrinsically activated as demonstrated with the $\beta$-catenin wild-type cell lines HuH7 and HEK293 after lithium chloride stimulation. Further, the cell lines used in this study harbor $\beta$-catenin mutations indicating that the molecules upstream of the destruction complex should not be needed for pathway activation/modulation. Therefore, knowing that aprepitant more likely acts at the level of $\beta$-catenin, we made several observations on how NK1R inhibition could modulate Wnt signaling.

One of our intriguing results was the discovery of increased membrane bound $\beta$-catenin upon aprepitant treatment that we believe could be the cause of Wnt inhibition. It is well established that the E-cadherin/ $\beta$-catenin complex association is tightly regulated by a complex interplay of phosphorylations. Indeed, previous work reported that E-cadherin phosphorylation at specific sites promotes cell adhesion by increasing the E-cadherin/ $\beta$-catenin (131) binding affinity. Particularly, the cytoplasmic domain of Ecadherin contains several phosphorylation sites for CKII and GSK3 $\beta$ (131). However, we found an increase of AKTdependent phosphorylation of GSK3 $\beta$ (S9), which is known to completely suppress its kinase activity (132). Therefore, it is unlikely that GSK3 $\beta$ is responsible for the observed effect. Other phosphorylation sites have been characterized in $\beta$ catenin as being central for the binding to E-cadherin. Particularly, Y142, Y489 and Y654 are phosphorylated by Fyn/c-Met, Abl/Fer and EGFR/Src, respectively, and enhanced activity of these kinases has been linked to a decrease of E-cadherin/ $\beta$-catenin binding affinity (133). However, our RPPA data revealed that total and phosphorylation levels of c-Met (Y1235), EGFR (Y1068/Y1173) and Src (Y416/Y527) were not affected.

In our group, we showed that FOXM1, a recognized shuttle protein for the translocation of $\beta$-catenin to the nucleus (134), was found inhibited at the mRNA and protein levels following inhibition of NK1R. Intriguingly, we also observed a loss of colocalization between these two proteins reflected by an increase of nuclear FOXM1 and membrane-bound $\beta$-catenin (Figure 2). Disruption of this complex could, therefore, be the cause of Wnt inhibition in Wnt-dependent cancer cells leading to enhanced susceptibility for apoptosis and growth arrest. In accordance, Zhang et al. showed that FOXM1 mutation or nuclear import prevented $\beta$-catenin nuclear accumulation in tumor cells, which led to a decrease in Wnt activity (134). Nevertheless, these findings do not explain how exactly $\beta$-catenin accumulates at the membrane. This finding is indeed very remarkable because it leads to the assumption that NK1R inhibition fortifies epithelial states of the cell, therefore, indicating a potential role of NK1R in the regulation of epithelial-mesenchymal transition (EMT). This process confers mesenchymal properties on epithelial cells and has been associated with the acquisition of aggressive traits participating in the outgrowth of metastasis (135). For this reason, approaches to reverse or inhibit this phenomenon in cancer cells are still intensively investigated (136). Additional experiments should, thus, focus on analyzing EMT regulation following aprepitant treatment, especially because Wnt and PI3K/AKT/mTOR pathways are important drivers (136, 137). For instance, an inquiry of EMT markers by qRTPCR (TWIST, SLUG, SNAIL, CDHI) (138), wound healing assay or Boyden chamber assays to assess invasiveness could be envisioned (139).

Our group was able to demonstrate that targeting NK1R with aprepitant abrogated canonical Wnt signaling in hepatoblastoma cell lines. More generally, we argue that aprepitant might have the same potency in cells in which the Wnt pathway is constitutively activated as already demonstrated in colorectal cancer cells in one of our complementary studies (111). The mechanism by which this effect is mediated is still partially obscure; it seems, however, to follow the same pattern. Indeed, upon aprepitant treatment a common key event found in all our models was the down-regulation of FOXM1. Emerging evidences support the crucial role of this protein in $\beta$-catenin/TCF4 transactivation. The latter was demonstrated in Foxm 1 knockout mice in which Wnt signaling was significantly reduced in Foxm 1-/- colon tumors (140). Further, Chen et al. recently reported new insights by finding that GSK3- $\beta$ mediates FOXM1 degradation in glioma cells and that activation of Wnt signaling increases the protein stability (141). Given the fact that this portein is highly expressed in cancer cells compared to non-tumorous tissues, it becomes evident that efforts need to be made toward the understanding of FOXM1 pathobiology in cancer. This could open new innovative treatment strategies and, as exposed in this review, be an alternative target for the treatment of Wntdependent cancers. 


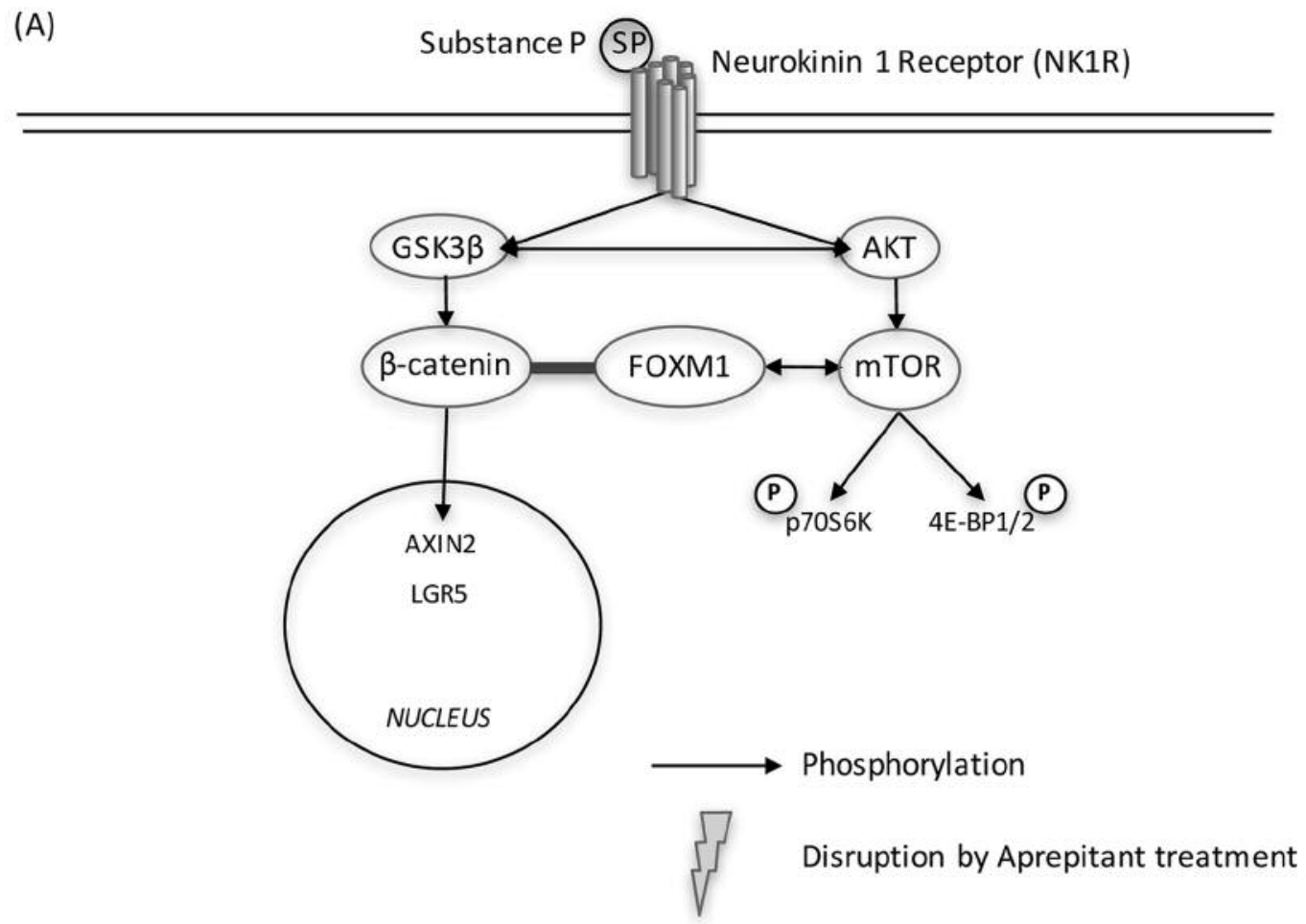

(B)

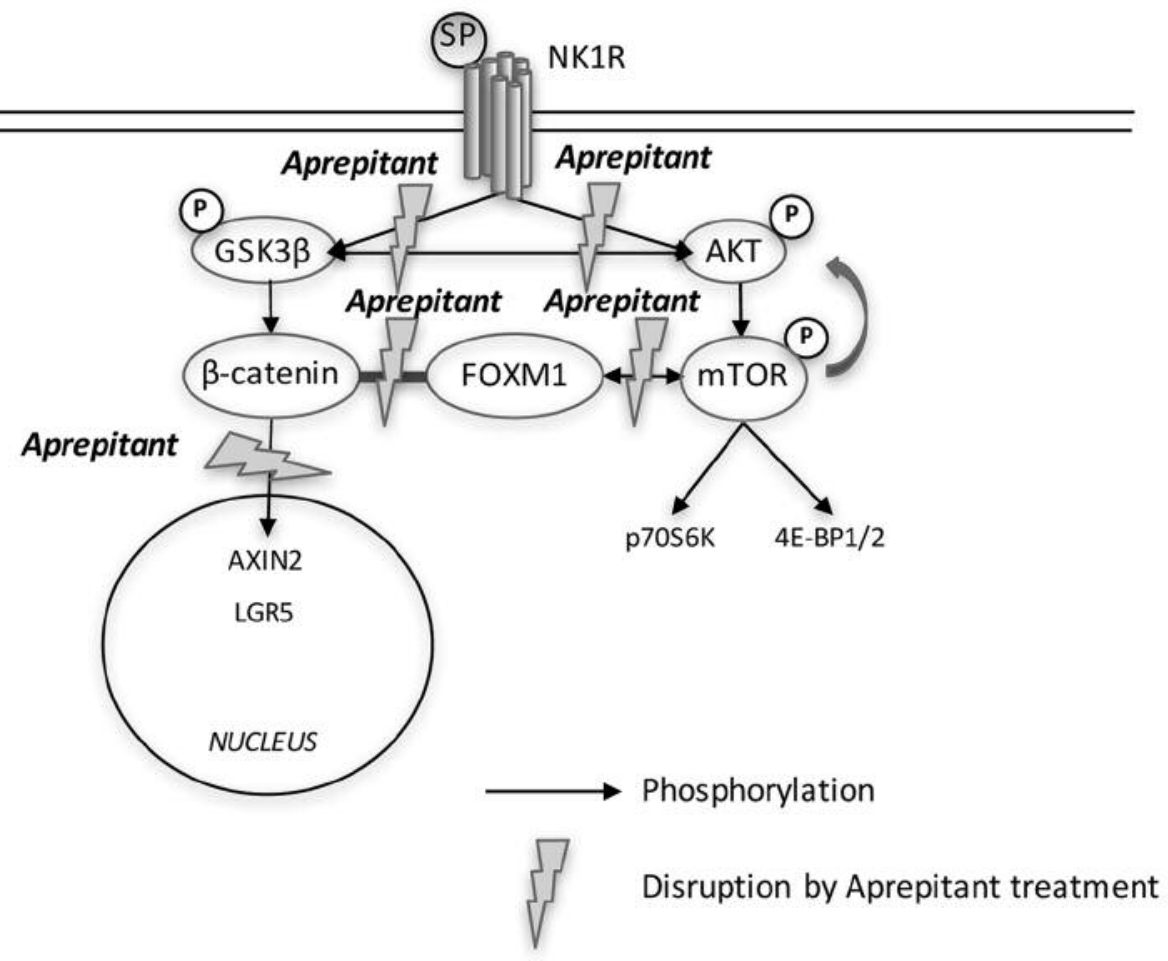

Figure 2. Graphical illustration of crosstalk between NK1R, PI3K/AKT/mTOR pathway and canonical Wnt signaling. (A) According to our data, the SP/NK1R system seems to positively influence downstream PI3K/AKT/mTOR (right side of the illustration) and Wnt signaling (left side of the illustration). (B) Upon blockage of NK1R with aprepitant, both phosphorylation sites of AKT (S473 and T308), as well as mTOR (S2448), become increasingly phosphorylated after 24 hours indicating an activation of upstream PI3K/AKT/mTOR signaling, whereas downstream actors of PI3K/AKT/mTOR ( $p 70 S 6 K$ and 4E-BP1/2) appear to be down-regulated. On the other hand, aprepitant treatment increases GSK3 $\beta$ phosphorylation but robustly inhibits canonical Wnt signaling as evidenced by decreased $\beta$-catenin, as well as down-regulated Wnt target genes AXIN2 and LGR5. The key mechanism for the latter seems to be disruption of the FOXM1- $\beta$-catenin interaction. Figure adapted from Ilmer et al. (107). 


\section{Crosslinks Between PI3K/AKT/mTOR and Canonical Wnt Signaling}

Crosslinks between PI3K/AKT/mTOR and Wnt signaling have been well described, although not in the setting of NK1R inhibition. Wnt can inhibit GSK3 $\beta$ to activate mTOR in the absence of $\beta$-catenin during regular cell growth. Inoki et al. reported that the kinases GSK3 $\beta$ and AMPK cooperate in the activation of TSC2 to inhibit mTOR activity (142). This work clearly showed that the phosphorylation of TSC 2 by GSK3 $\beta$ is significantly suppressed by Wnt signaling. Furthermore, mTORC1 activity has been shown to facilitate nuclear translocation of Forkhead Box K1 (FOXK1), another member of the forkhead family, which is predicted to contain an mTOR phosphorylation motif (143). We speculate here that FOXM1 might be modulated in a similar way since it shares a common forkhead domain (144). Increase of nuclear mTOR (S2448) could, therefore, induce the sequestration of FOXM1 in the nucleus, which ultimately would inhibit Wnt signaling. Unfortunately, at this time, there is not enough evidence that would permit to fully answer this intriguing query.

Apart from this, another crosslink between PI3K/AKT/ mTOR and Wnt has been recently described. Gao et al. showed that autophagy negatively regulates Wnt signaling by promoting Dishevelled 2 degradation (145). Autophagy is an early mechanism set up by the cells under nutrient starvation, stress or reduced availability of growth factors to adjust the metabolism to survive. It is essentially activated upon mTORC1 inhibition $(146,147)$. However, we exclude this possibility as hepatoblastoma cells harbor $\beta$-catenin mutation and should theoretically be independent of upstream signals.

\section{Targeting Cancer Stem Cells in Hepatoblastoma}

High Wnt signaling has been associated with stemness property (148), such as in colorectal cancer (149) or in susceptible pancreatic cancer cells (150). Our recent work revealed in vitro that aprepitant not only diminished the sphere formation ability of hepatoblastoma cells when treated simultaneously but also sustainably altered their stemness potential, as shown by sphere formation ability assays of pretreated hepatoblastoma cells and decreased expression of embryonic stemness genes. Interestingly, we found that high expression of embryonic stemness markers correlated with high expression of $N K 1 R$-tr in HepT1 and HuH7 spheres suggesting a mutual dependency. However, it seems unlikely that this mechanism solely relies on Wnt signaling as, contrary to HepT1, HuH7 spheres did not overexpress members of the Wnt pathway (LGR5, CTNNB1, AXIN2). More interestingly, treatment of spheres with aprepitant only affected Wnt mutated cell lines when considering embryonic markers and NKIR expression. This suggests the presence of a positive feedback loop in Wnt mutated cells between
NK1R-tr and Wnt signaling, which is potentially pivotal in the acquisition of stem-like features. This highlights, once again, the central role of this isoform as a driver of hepatoblastoma and indicates that it could be used as a marker of agressiveness. Taken together, there is now evidence that NK1R antagonism decreases canonical Wnt signaling and stemness property, especially in Wnt-dependent cancer stem cells (CSC)-like cells. These results are of particular importance considering the assumption that CSC are responsible for cancer relapse and resistance (151).

However, this is not to say that growth inhibition following treatment with NK1R antagonists in hepatoblastoma cells is necessarily triggered exclusively through this mechanism. For example, cancer cells that exhibit little Wnt activity, such as HuH7 cells, still show a therapeutic effect in response to aprepitant. Often, this therapeutic response is in the same magnitude as in cancer cells with high Wnt activity. This goes along with our findings, which identify other important cancer pathways being significantly inhibited by NK1R antagonists, such as PI3K/AKT/mTOR. Overall, we find these results encouraging because targeting two pathways involved in tumorigenesis might delay the development of escape mechanisms in the cancer cell.

\section{The NK1R as an Anti-tumor Target in Hepatoblastoma in the Clinical Context}

Recent data clearly identifies NK1R as a potent antitumor target in hepatoblastoma. One central question regarding the expression of NK1R is whether or not it correlates with clinical features and prognosis in hepatoblastoma. Such knowledge could carry importance in a clinical setting, for example, to predict either prognosis and/or a treatment response with NK1R antagonists. Such a correlation has been described for the expression rate of the SP/NK1R complex and prognosis in other pediatric tumors $(110,152-154)$. For example, Garcia-Recio et al. found that SP contributes to persistent transmodulation of the ErbB receptors, EGFR and HER2, in breast cancer, where it enhances malignancy and therapeutic resistance (110). Both NKIR and TACl (SP) were highly expressed in HER2+ primary breast tumors and correlated with poor prognosis factors. Interestingly, in their study, upon treatment of xenografted mice bearing HER2+ or HER2- human breast carcinoma, they found a therapeutic effect only for HER $2+$ tumors suggesting that the anti-tumor effects of NK1R inhibition in carcinoma of the breast depended on the modulatory properties of NK1R signaling on the activity of HER2 and EGFR (110).

Essentially nothing is known regarding the expression profile of $N K 1 R$ and a possible association with clinical features in hepatoblastoma. Therefore, our group recently performed an in-depth analysis of the expression pattern of $N K 1 R$ in hepatoblastoma and correlated these findings with 
clinical data on tumor stage, biology and outcome of 47 children with hepatoblastoma treated in Germany (155).

Compared to tumor-free liver tissue, the tumorous tissue of these children expressed significantly more truncated $N K 1 R$ compared to non-tumours control tissue. This effect was statistically significant. These in vivo findings are in accordance with findings in vitro. When we analyzed the expression of $N K 1 R$-fl, however, no such different expression pattern was found. These findings further support the notion that it is the NK1R-tr, rather than the NK1R-fl, which is associated with cancer. With this background, it was interesting to analyze the expression of both variants of NK1R solely within the tumorous tissues. Interestingly, the expression of the full-length version correlated with the expression of the truncated version. We explain this with the simple fact that both proteins are synthesized by the same cellular mechanisms and one merely resembles a splice variation of the other.

Despite the clear observation that NK1R-tr is overexpressed in hepatoblastoma compared to non-tumorous liver tissue, in our analysis, we could not detect any correlation with clinical features, such as the presence of metastasis, PRETEXT, vascular invasion, histology, age of diagnosis, multifocality, CTNNB1 mutation, gender and overall survival.

Two tumor subclasses within hepatoblastoma resembling distinct phases of liver development and a discriminating 16gene signature have been described $(32,156)$. Intriguingly, when separated into the two groups by this 16-gene signature, namely $\mathrm{C} 1$ and $\mathrm{C} 2$, clinical prognosis could be predicted for these children with very high accuracy (32). By retrieving the $\mathrm{C} 1 / \mathrm{C} 2$-status from our hepatoblastoma database that classified each tumor according to this specific 16-gene signature, we found that $N K 1 R$-fl was lower in the $\mathrm{C} 2$ signature compared to $\mathrm{C} 1$ in our analysis. As mentioned above, we noted a worse prognosis with low expression of NK1R-tr and, when further analyzing the $\mathrm{C} 2$ signature population separately, we again found worse prognosis with low expression of $N K 1 R$-tr. We conclude from this data that, in hepatoblastoma, NK1R alone cannot be used as a prognostic clinical marker. However, $N K 1 R$-tr could possibly help to identify tumors with an advanced stage, potentially by itself and especially within the C2 signature patient population. More in-depth analysis of such a C2 NK1R-tr low tumor cohort will be necessary to demonstrate the value of this distinction.

One additional aspect to consider is the fact that most of the patients we analyzed had previously received chemotherapy. Cairo et al. observed that the 16-gene signature is stable irrespective of pretreatment; however, we do not know if this also holds true for the expression pattern of NK1R. Nevertheless, this knowledge is important because the exposure to chemotherapy could potentially alter the expression pattern of $N K 1 R$ and its splice variants. What we have learned is that the $N K 1 R$ expression pattern does not seem to depend on or predict the clinical stage and behavior. Rather, our data provides evidence that hepatoblastoma may ubiquitously express $N K 1 R$, thus supporting recent evidence that NK1R antagonists could be a promising anticancer agents against a wide variety of hepatoblastoma subsets (157).

\section{Conclusion}

Understanding the biology of hepatoblastoma has great therapeutic implications for a large variety of cancers, especially those that are considered to be "addicted" to or originate from increased Wnt-signaling. NK1R interacts with Wnt via disrupting/stabilizing the $\beta$-catenin-FOXM1 complex and, thereby, regulates its activity. This makes the NK1R/SP receptor complex an innovative and attractive anticancer target for a large variety of cancers, including hepatoblastoma. Yet, many questions remain unsolved, such as the exact role of the expression of different splice variants of the NK1R, as well as the correlation of the NK1R with prognosis. More sophisticated research is necessary to unravel the exact implications of targeting NK1R/Wnt to achieve the maximum desired clinical effect.

\section{Conflicts of Interest}

The Authors declare that they have no conflict of interest.

\section{Acknowledgements}

M. Berger and M. Ilmer were supported by postdoctoral stipends of the German Academic Exchange Program (DAAD). M. Berger was additionally funded by the Friedrich-Baur Foundation Munich, Münchener Medizinische Wochenschrift, as well as the Förderung für Forschung und Lehre of LMU University. R. Kappler obtained funding from the Bettina Bräu Foundation, Munich, and the Gänseblümchen-Voerde Foundation, Voerde. This work bases in part on the PhD-Thesis of $\mathrm{A}$. Garnier, which she carried out at the Ludwig-Maximilians-University in Munich, Germany. Parts of this manuscript are similar or identical to the PhD-Thesis.

\section{References}

1 Allan BJ, Parikh PP, Diaz S, Perez EA, Neville HL and Sola JE: Predictors of survival and incidence of hepatoblastoma in the paediatric population. HPB (Oxford) 15(10): 741-746, 2013.

2 Schnater JM, Kohler SE, Lamers WH, von Schweinitz D and Aronson DC: Where do we stand with hepatoblastoma? A review. Cancer 98(4): 668-678, 2003.

3 DeBaun MR and Tucker MA: Risk of cancer during the first four years of life in children from the beckwith-wiedemann syndrome registry. J Pediatr 132(3 Pt 1): 398-400, 1998.

4 Hughes LJ and Michels VV: Risk of hepatoblastoma in familial adenomatous polyposis. Am J Med Genet 43(6): 1023-1025, 1992. 
5 Ikeda $\mathrm{H}$, Matsuyama $\mathrm{S}$ and Tanimura M: Association between hepatoblastoma and very low birth weight: A trend or a chance? J Pediatr 130(4): 557-560, 1997.

6 von Schweinitz D, Burger D, Bode U, Weinel P, Erttmann R, Hecker $\mathrm{H}$ and Mildenberger $\mathrm{H}$ : Results of the hb-89 study in treatment of malignant epithelial liver tumors in childhood and concept of a new hb-94 protocol. Klin Padiatr 206(4): 282-288, 1994.

7 Perilongo G, Brown J, Shafford E, Brock P, De Camargo B, Keeling JW, Vos A, Philips A, Pritchard J and Plaschkes J: Hepatoblastoma presenting with lung metastases: Treatment results of the first cooperative, prospective study of the international society of paediatric oncology on childhood liver tumors. Cancer 89(8): 1845-1853, 2000.

8 Herzog CE, Andrassy RJ and Eftekhari F: Childhood cancers: Hepatoblastoma. Oncologist 5(6): 445-453, 2000.

9 Haas JE, Feusner JH and Finegold MJ: Small cell undifferentiated histology in hepatoblastoma may be unfavorable. Cancer 92(12): 3130-3134, 2001.

10 Maibach R, Roebuck D, Brugieres L, Capra M, Brock P, Dall'Igna P, Otte JB, De Camargo B, Zsiros J, Zimmermann A, Aronson D, Childs M, Scopinaro M, Morland B, Plaschkes J, Czauderna $\mathrm{P}$ and Perilongo G: Prognostic stratification for children with hepatoblastoma: The siopel experience. Eur J Cancer 48(10): 1543-1549, 2012.

11 Hishiki T: Current therapeutic strategies for childhood hepatic tumors: Surgical and interventional treatments for hepatoblastoma. Int J Clin Oncol 18(6): 962-968, 2013.

12 Haeberle B and Schweinitz D: Treatment of hepatoblastoma in the german cooperative pediatric liver tumor studies. Front Biosci (Elite Ed) 4: 493-498, 2012.

13 Malogolowkin MH, Katzenstein HM, Krailo M and Meyers RL: Treatment of hepatoblastoma: The north american cooperative group experience. Front Biosci (Elite Ed) 4: 17171723, 2012.

14 Czauderna P, Lopez-Terrada D, Hiyama E, Haberle B, Malogolowkin MH and Meyers RL: Hepatoblastoma state of the art: Pathology, genetics, risk stratification, and chemotherapy. Curr Opin Pediatr 26(1): 19-28, 2014.

15 Roebuck DJ, Aronson D, Clapuyt P, Czauderna P, de Ville de Goyet J, Gauthier F, Mackinlay G, Maibach R, McHugh K, Olsen OE, Otte JB, Pariente D, Plaschkes J, Childs M and Perilongo G: 2005 pretext: A revised staging system for primary malignant liver tumours of childhood developed by the siopel group. Pediatr Radiol 37(2): 123-132; quiz 249-150, 2007.

16 Purcell R, Childs M, Maibach R, Miles C, Turner C, Zimmermann A, Czauderna $\mathrm{P}$ and Sullivan $\mathrm{M}$ : Potential biomarkers for hepatoblastoma: Results from the siopel-3 study. Eur J Cancer 48(12): 1853-1859, 2012.

17 Klaus A and Birchmeier W: Wnt signalling and its impact on development and cancer. Nat Rev Cancer 8(5): 387-398, 2008.

18 Apte U, Zeng G, Thompson MD, Muller P, Micsenyi A, Cieply B, Kaestner KH and Monga SP: Beta-catenin is critical for early postnatal liver growth. Am J Physiol Gastrointest Liver Physiol 292(6): G1578-1585, 2007.

19 Tan X, Yuan Y, Zeng G, Apte U, Thompson MD, Cieply B, Stolz DB, Michalopoulos GK, Kaestner KH and Monga SP: Beta-catenin deletion in hepatoblasts disrupts hepatic morphogenesis and survival during mouse development. Hepatology 47(5): 1667-1679, 2008.
20 Monga SP: Role and regulation of beta-catenin signaling during physiological liver growth. Gene Expr 16(2): 51-62, 2014.

21 Planas-Paz L, Orsini V, Boulter L, Calabrese D, Pikiolek M, Nigsch F, Xie Y, Roma G, Donovan A, Marti P, Beckmann N, Dill MT, Carbone W, Bergling S, Isken A, Mueller M, Kinzel B, Yang Y, Mao X, Nicholson TB, Zamponi R, Capodieci P, Valdez R, Rivera D, Loew A, Ukomadu C, Terracciano LM, Bouwmeester T, Cong F, Heim MH, Forbes SJ, Ruffner H and Tchorz JS: The rspo-lgr4/5-znrf3/rnf43 module controls liver zonation and size. Nat Cell Biol 18(5): 467-479, 2016.

22 Monga SP: Role of wnt/beta-catenin signaling in liver metabolism and cancer. Int J Biochem Cell Biol 43(7): 10211029, 2011.

23 Monga SP, Pediaditakis P, Mule K, Stolz DB and Michalopoulos GK: Changes in wnt/beta-catenin pathway during regulated growth in rat liver regeneration. Hepatology 33(5): 1098-1109, 2001.

24 Michalopoulos GK: Liver regeneration after partial hepatectomy: Critical analysis of mechanistic dilemmas. Am J Pathol 176(1): 2-13, 2010.

25 Michalopoulos GK and DeFrances MC: Liver regeneration. Science 276(5309): 60-66, 1997.

26 Polakis P: Wnt signaling and cancer. Genes Dev 14(15): 18371851, 2000.

27 Koch A, Denkhaus D, Albrecht S, Leuschner I, von Schweinitz $\mathrm{D}$ and Pietsch T: Childhood hepatoblastomas frequently carry a mutated degradation targeting box of the beta-catenin gene. Cancer Res 59(2): 269-273, 1999.

28 Koesters R and von Knebel Doeberitz M: The wnt signaling pathway in solid childhood tumors. Cancer Lett 198(2): 123138, 2003.

29 eng YM, Wu MZ, Mao TL, Chang MH and Hsu HC: Somatic mutations of beta-catenin play a crucial role in the tumorigenesis of sporadic hepatoblastoma. Cancer Lett 152(1): 45-51, 2000.

30 Takayasu H, Horie H, Hiyama E, Matsunaga T, Hayashi Y, Watanabe Y, Suita S, Kaneko M, Sasaki F, Hashizume K, Ozaki $\mathrm{T}$, Furuuchi K, Tada M, Ohnuma $\mathrm{N}$ and Nakagawara A: Frequent deletions and mutations of the beta-catenin gene are associated with overexpression of cyclin $\mathrm{d} 1$ and fibronectin and poorly differentiated histology in childhood hepatoblastoma. Clin Cancer Res 7(4): 901-908, 2001.

31 Wei Y, Fabre M, Branchereau S, Gauthier F, Perilongo G and Buendia MA: Activation of beta-catenin in epithelial and mesenchymal hepatoblastomas. Oncogene 19(4): 498-504, 2000.

32 Cairo S, Armengol C, De Reynies A, Wei Y, Thomas E, Renard CA, Goga A, Balakrishnan A, Semeraro M, Gresh L, Pontoglio M, Strick-Marchand H, Levillayer F, Nouet Y, Rickman D, Gauthier F, Branchereau S, Brugieres L, Laithier V, Bouvier R, Boman F, Basso G, Michiels JF, Hofman P, Arbez-Gindre F, Jouan H, Rousselet-Chapeau MC, Berrebi D, Marcellin L, Plenat F, Zachar D, Joubert M, Selves J, Pasquier D, BioulacSage P, Grotzer M, Childs M, Fabre M and Buendia MA: Hepatic stem-like phenotype and interplay of wnt/beta-catenin and myc signaling in aggressive childhood liver cancer. Cancer Cell 14(6): 471-484, 2008.

33 Taniguchi K, Roberts LR, Aderca IN, Dong X, Qian C, Murphy LM, Nagorney DM, Burgart LJ, Roche PC, Smith DI, Ross JA and Liu W: Mutational spectrum of beta-catenin, axin1, and axin2 in hepatocellular carcinomas and hepatoblastomas. Oncogene 21(31): 4863-4871, 2002. 
34 Koch A, Weber N, Waha A, Hartmann W, Denkhaus D, Behrens J, Birchmeier W, von Schweinitz D and Pietsch T: Mutations and elevated transcriptional activity of conductin (axin2) in hepatoblastomas. J Pathol 204(5): 546-554, 2004.

35 Aretz S, Koch A, Uhlhaas S, Friedl W, Propping P, von Schweinitz D and Pietsch T: Should children at risk for familial adenomatous polyposis be screened for hepatoblastoma and children with apparently sporadic hepatoblastoma be screened for apc germline mutations? Pediatr Blood Cancer 47(6): 811$818,2006$.

36 Oda H, Imai Y, Nakatsuru Y, Hata J and Ishikawa T: Somatic mutations of the apc gene in sporadic hepatoblastomas. Cancer Res 56(14): 3320-3323, 1996.

37 Koch A, Waha A, Hartmann W, Hrychyk A, Schuller U, Wharton KA Jr., Fuchs SY, von Schweinitz D and Pietsch T: Elevated expression of wnt antagonists is a common event in hepatoblastomas. Clin Cancer Res 11(12): 4295-4304, 2005.

38 He TC, Sparks AB, Rago C, Hermeking H, Zawel L, da Costa LT, Morin PJ, Vogelstein B and Kinzler KW: Identification of c-myc as a target of the apc pathway. Science 281(5382): 1509$1512,1998$.

39 Haegebarth A and Clevers H: Wnt signaling, lgr5, and stem cells in the intestine and skin. Am J Pathol 174(3): 715-721, 2009.

40 Cavard C, Colnot S, Audard V, Benhamouche S, Finzi L, Torre C, Grimber G, Godard C, Terris B and Perret C: Wnt/betacatenin pathway in hepatocellular carcinoma pathogenesis and liver physiology. Future Oncol 4(5): 647-660, 2008

41 Burke ZD, Reed KR, Phesse TJ, Sansom OJ, Clarke AR and Tosh D: Liver zonation occurs through a beta-catenindependent, c-myc-independent mechanism. Gastroenterology 136(7): 2316-2324 e2311-2313, 2009.

42 MacDonald BT, Tamai $\mathrm{K}$ and $\mathrm{He} \mathrm{X}$ : Wnt/beta-catenin signaling: Components, mechanisms, and diseases. Dev Cell 17(1): 9-26, 2009.

43 Nusse R, Brown A, Papkoff J, Scambler P, Shackleford G, McMahon A, Moon R and Varmus H: A new nomenclature for int-1 and related genes: The wnt gene family. Cell 64(2): 231, 1991.

44 Testa JR and Tsichlis PN: Akt signaling in normal and malignant cells. Oncogene 24(50): 7391-7393, 2005.

45 Hartmann W, Kuchler J, Koch A, Friedrichs N, Waha A, Endl E, Czerwitzki J, Metzger D, Steiner S, Wurst P, Leuschner I, von Schweinitz D, Buettner R and Pietsch T: Activation of phosphatidylinositol-3'-kinase/akt signaling is essential in hepatoblastoma survival. Clin Cancer Res 15(14): 4538-4545, 2009.

46 olivka J, Jr. and Janku F: Molecular targets for cancer therapy in the pi3k/akt/mtor pathway. Pharmacol Ther 142(2): 164-175, 2014.

47 Altomare DA and Testa JR: Perturbations of the akt signaling pathway in human cancer. Oncogene 24(50): 7455-7464, 2005.

48 Lemmon MA and Schlessinger J: Cell signaling by receptor tyrosine kinases. Cell 141(7): 1117-1134, 2010.

49 Gray SG, Eriksson T, Ekstrom C, Holm S, von Schweinitz D, Kogner P, Sandstedt B, Pietsch T and Ekstrom TJ: Altered expression of members of the igf-axis in hepatoblastomas. Br J Cancer 82(9): 1561-1567, 2000.

50 Rosen CJ and Pollak M: Circulating igf-i: New perspectives for a new century. Trends Endocrinol Metab 10(4): 136-141, 1999.
51 Rainier S, Dobry CJ and Feinberg AP: Loss of imprinting in hepatoblastoma. Cancer Res 55(9): 1836-1838, 1995.

52 Akmal SN, Yun K, MacLay J, Higami Y and Ikeda T: Insulinlike growth factor 2 and insulin-like growth factor binding protein 2 expression in hepatoblastoma. Hum Pathol 26(8): 846$851,1995$.

53 Regel I, Eichenmuller M, Joppien S, Liebl J, Haberle B, MullerHocker J, Vollmar A, von Schweinitz D and Kappler R: Igfbp3 impedes aggressive growth of pediatric liver cancer and is epigenetically silenced in vascular invasive and metastatic tumors. Mol Cancer 11: 9, 2012.

54 Eichenmüller M, Gruner I, Hagl B, Häberle B, Müller-Höcker J, von Schweinitz D and Kappler R: Blocking the hedgehog pathway inhibits hepatoblastoma growth. Hepatology 49(2): 482-490, 2009.

55 Litten JB, Chen TT, Schultz R, Herman K, Comstock J, Schiffman J, Tomlinson GE and Rakheja D: Activated notch2 is overexpressed in hepatoblastomas: An immunohistochemical study. Pediatr Dev Pathol 14(5): 378-383, 2011.

56 Tanimizu $\mathrm{N}$ and Miyajima A: Notch signaling controls hepatoblast differentiation by altering the expression of liverenriched transcription factors. J Cell Sci 117(Pt 15): 3165-3174, 2004.

57 Sakamoto LH, B DEC, Cajaiba M, Soares FA and Vettore AL: Mt1g hypermethylation: A potential prognostic marker for hepatoblastoma. Pediatr Res 67(4): 387-393, 2010.

58 Weber RG, Pietsch T, von Schweinitz D and Lichter P: Characterization of genomic alterations in hepatoblastomas. A role for gains on chromosomes $8 \mathrm{q}$ and 20 as predictors of poor outcome. Am J Pathol 157(2): 571-578, 2000.

59 Khaderi S, Guiteau J, Cotton RT, O'Mahony C, Rana A and Goss JA: Role of liver transplantation in the management of hepatoblastoma in the pediatric population. World $\mathrm{J}$ Transplant 4(4): 294-298, 2014.

60 Ortega JA, Douglass EC, Feusner JH, Reynolds M, Quinn JJ, Finegold MJ, Haas JE, King DR, Liu-Mares W, Sensel MG and Krailo MD: Randomized comparison of cisplatin/vincristine/ fluorouracil and cisplatin/continuous infusion doxorubicin for treatment of pediatric hepatoblastoma: A report from the children's cancer group and the pediatric oncology group. J Clin Oncol 18(14): 2665-2675, 2000.

61 Aronson DC, Czauderna P, Maibach R, Perilongo G and Morland B: The treatment of hepatoblastoma: Its evolution and the current status as per the siopel trials. J Indian Assoc Pediatr Surg 19(4): 201-207, 2014.

62 Meyers RL, Tiao G, de Ville de Goyet J, Superina R and Aronson DC: Hepatoblastoma state of the art: Pre-treatment extent of disease, surgical resection guidelines and the role of liver transplantation. Curr Opin Pediatr 26(1): 29-36, 2014.

63 Kremer N, Walther AE and Tiao GM: Management of hepatoblastoma: An update. Curr Opin Pediatr 26(3): 362-369, 2014.

64 Malogolowkin MH, Katzenstein HM, Meyers RL, Krailo MD, Rowland JM, Haas J and Finegold MJ: Complete surgical resection is curative for children with hepatoblastoma with pure fetal histology: A report from the children's oncology group. J Clin Oncol 29(24): 3301-3306, 2011.

65 D'Antiga L, Vallortigara F, Cillo U, Talenti E, Rugge M, Zancan L, Dall'Igna P, De Salvo GL and Perilongo G: Features predicting unresectability in hepatoblastoma. Cancer 110(5): 1050-1058, 2007. 
66 Browne M, Sher D, Grant D, Deluca E, Alonso E, Whitington $\mathrm{PF}$ and Superina RA: Survival after liver transplantation for hepatoblastoma: A 2-center experience. J Pediatr Surg 43(11): 1973-1981, 2008.

67 Meyers RL, Rowland JR, Krailo M, Chen Z, Katzenstein HM and Malogolowkin MH: Predictive power of pretreatment prognostic factors in children with hepatoblastoma: A report from the children's oncology group. Pediatr Blood Cancer 53(6): 1016-1022, 2009.

68 Warmann S, Hunger M, Teichmann B, Flemming P, Gratz KF and Fuchs J: The role of the mdr1 gene in the development of multidrug resistance in human hepatoblastoma: Clinical course and in vivo model. Cancer 95(8): 1795-1801, 2002.

69 Kimura Y, Morita SY, Matsuo M and Ueda K: Mechanism of multidrug recognition by mdr1/abcb1. Cancer Sci 98(9): 13031310, 2007.

70 Morland B: Commentary on hepatoblastoma minisymposium. Pediatr Radiol 36(3): 175, 2006.

71 Ichikawa Y, Ghanefar M, Bayeva M, Wu R, Khechaduri A, Naga Prasad SV, Mutharasan RK, Naik TJ and Ardehali H: Cardiotoxicity of doxorubicin is mediated through mitochondrial iron accumulation. J Clin Invest 124(2): 617-630, 2014.

72 Pennefather JN, Lecci A, Candenas ML, Patak E, Pinto FM and Maggi CA: Tachykinins and tachykinin receptors: A growing family. Life Sci 74(12): 1445-1463, 2004.

73 Page NM: Characterization of the gene structures, precursor processing and pharmacology of the endokinin peptides. Vascul Pharmacol 45(4): 200-208, 2006.

74 Otsuka $\mathrm{M}$ and Yoshioka K: Neurotransmitter functions of mammalian tachykinins. Physiol Rev 73(2): 229-308, 1993.

75 Almeida TA, Rojo J, Nieto PM, Pinto FM, Hernandez M, Martin JD and Candenas ML: Tachykinins and tachykinin receptors: Structure and activity relationships. Curr Med Chem 11(15): 2045-2081, 2004.

76 Tsuchida K, Shigemoto R, Yokota Y and Nakanishi S: Tissue distribution and quantitation of the mrnas for three rat tachykinin receptors. Eur J Biochem 193(3): 751-757, 1990.

77 Ho WZ, Lai JP, Zhu XH, Uvaydova M and Douglas SD: Human monocytes and macrophages express substance $\mathrm{p}$ and neurokinin-1 receptor. J Immunol 159(11): 5654-5660, 1997.

78 Patacchini R and Maggi CA: Peripheral tachykinin receptors as targets for new drugs. Eur J Pharmacol 429(1-3): 13-21, 2001.

79 Saffroy M, Torrens Y, Glowinski J and Beaujouan JC: Autoradiographic distribution of tachykinin nk2 binding sites in the rat brain: Comparison with $\mathrm{nk} 1$ and $\mathrm{nk} 3$ binding sites. Neuroscience 116(3): 761-773, 2003.

80 Gerard NP, Garraway LA, Eddy RL, Jr., Shows TB, Iijima H, Paquet JL and Gerard C: Human substance p receptor (nk-1): Organization of the gene, chromosome localization, and functional expression of cdna clones. Biochemistry 30(44): 10640-10646, 1991.

81 Roush ED and Kwatra MM: Human substance p receptor expressed in chinese hamster ovary cells directly activates g(alpha q/11), g(alpha s), g(alpha o). FEBS Lett 428(3): 291 294, 1998.

82 Mitsuhashi M, Ohashi Y, Shichijo S, Christian C, SudduthKlinger J, Harrowe G and Payan DG: Multiple intracellular signaling pathways of the neuropeptide substance p receptor. J Neurosci Res 32(3): 437-443, 1992.
83 Sagan S, Chassaing G, Pradier L and Lavielle S: Tachykinin peptides affect differently the second messenger pathways after binding to cho-expressed human nk-1 receptors. J Pharmacol Exp Ther 276(3): 1039-1048, 1996.

84 Takeda Y, Blount P, Sachais BS, Hershey AD, Raddatz R and Krause JE: Ligand binding kinetics of substance $p$ and neurokinin a receptors stably expressed in chinese hamster ovary cells and evidence for differential stimulation of inositol 1,4,5trisphosphate and cyclic amp second messenger responses. J Neurochem 59(2): 740-745, 1992.

85 Khawaja AM and Rogers DF: Tachykinins: Receptor to effector. Int J Biochem Cell Biol 28(7): 721-738, 1996.

86 Holst B, Hastrup H, Raffetseder U, Martini L and Schwartz TW: Two active molecular phenotypes of the tachykinin nk1 receptor revealed by g-protein fusions and mutagenesis. J Biol Chem 276(23): 19793-19799, 2001.

87 Ramkissoon SH, Patel HJ, Taborga M and Rameshwar P: G protein-coupled receptors in haematopoietic disruption. Expert Opin Biol Ther 6(2): 109-120, 2006.

88 Nakajima Y, Tsuchida K, Negishi M, Ito S and Nakanishi S: Direct linkage of three tachykinin receptors to stimulation of both phosphatidylinositol hydrolysis and cyclic amp cascades in transfected chinese hamster ovary cells. J Biol Chem 267(4): 2437-2442, 1992.

89 Mantyh PW, Allen CJ, Ghilardi JR, Rogers SD, Mantyh CR, Liu H, Basbaum AI, Vigna SR and Maggio JE: Rapid endocytosis of a $g$ protein-coupled receptor: Substance $p$ evoked internalization of its receptor in the rat striatum in vivo. Proc Natl Acad Sci USA 92(7): 2622-2626, 1995.

90 Garland AM, Grady EF, Lovett M, Vigna SR, Frucht MM, Krause JE and Bunnett NW: Mechanisms of desensitization and resensitization of $\mathrm{g}$ protein-coupled neurokinin1 and neurokinin2 receptors. Mol Pharmacol 49(3): 438-446, 1996.

91 Roosterman D, Cottrell GS, Schmidlin F, Steinhoff M and Bunnett NW: Recycling and resensitization of the neurokinin 1 receptor. Influence of agonist concentration and rab gtpases. J Biol Chem 279(29): 30670-30679, 2004.

92 Fong TM, Anderson SA, Yu H, Huang RR and Strader CD: Differential activation of intracellular effector by two isoforms of human neurokinin-1 receptor. Mol Pharmacol 41(1): 24-30, 1992.

93 Page NM: New challenges in the study of the mammalian tachykinins. Peptides 26(8): 1356-1368, 2005.

94 Li H, Leeman SE, Slack BE, Hauser G, Saltsman WS, Krause JE, Blusztajn JK and Boyd ND: A substance p (neurokinin-1) receptor mutant carboxyl-terminally truncated to resemble a naturally occurring receptor isoform displays enhanced responsiveness and resistance to desensitization. Proc Natl Acad Sci USA 94(17): 9475-9480, 1997.

95 Harrison S and Geppetti P: Substance p. Int J Biochem Cell Biol 33(6): 555-576, 2001.

96 Tattersall FD, Rycroft W, Cumberbatch M, Mason G, Tye S, Williamson DJ, Hale JJ, Mills SG, Finke PE, MacCoss M, Sadowski S, Ber E, Cascieri M, Hill RG, MacIntyre DE and Hargreaves RJ: The novel nk1 receptor antagonist mk-0869 (1$754,030)$ and its water soluble phosphoryl prodrug, 1-758,298, inhibit acute and delayed cisplatin-induced emesis in ferrets. Neuropharmacology 39(4): 652-663, 2000.

97 Dando TM and Perry CM: Aprepitant: A review of its use in the prevention of chemotherapy-induced nausea and vomiting. Drugs 64(7): 777-794, 2004. 
98 Munoz M, Rosso M and Covenas R: A new frontier in the treatment of cancer: Nk-1 receptor antagonists. Curr Med Chem 17(6): 504-516, 2010.

99 Munoz M, Berger M, Rosso M, Gonzalez-Ortega A, Carranza A and Covenas R: Antitumor activity of neurokinin-1 receptor antagonists in mg-63 human osteosarcoma xenografts. Int $\mathrm{J}$ Oncol 44(1): 137-146, 2014.

100 Berger M, Neth O, Ilmer M, Garnier A, Salinas-Martin MV, de Agustin Asencio JC, von Schweinitz D, Kappler R and Munoz M: Hepatoblastoma cells express truncated neurokinin-1 receptor and can be growth inhibited by aprepitant in vitro and in vivo. J Hepatol 60(5): 985-994, 2014.

101 Rosso M, Munoz M and Berger M: The role of neurokinin-1 receptor in the microenvironment of inflammation and cancer. ScientificWorldJournal 2012: 381434, 2012.

102 Colotta F, Allavena P, Sica A, Garlanda C and Mantovani A: Cancer-related inflammation, the seventh hallmark of cancer: Links to genetic instability. Carcinogenesis 30(7): 1073-1081, 2009.

103 Mayordomo C, Garcia-Recio S, Ametller E, FernandezNogueira P, Pastor-Arroyo EM, Vinyals L, Casas I, Gascon P and Almendro V: Targeting of substance $\mathrm{p}$ induces cancer cell death and decreases the steady state of egfr and her2. J Cell Physiol 227(4): 1358-1366, 2012.

104 Patel HJ, Ramkissoon SH, Patel PS and Rameshwar P: Transformation of breast cells by truncated neurokinin-1 receptor is secondary to activation by preprotachykinin-a peptides. Proc Natl Acad Sci USA 102(48): 17436-17441, 2005.

105 Ramkissoon SH, Patel PS, Taborga M and Rameshwar P: Nuclear factor-kappab is central to the expression of truncated neurokinin-1 receptor in breast cancer: Implication for breast cancer cell quiescence within bone marrow stroma. Cancer Res 67(4): 1653-1659, 2007.

106 Gillespie E, Leeman SE, Watts LA, Coukos JA, O'Brien MJ, Cerda SR, Farraye FA, Stucchi AF and Becker JM: Truncated neurokinin-1 receptor is increased in colonic epithelial cells from patients with colitis-associated cancer. Proc Natl Acad Sci USA 108(42): 17420-17425, 2011.

107 Ilmer M, Garnier A, Vykoukal J, Alt E, von Schweinitz D, Kappler R and Berger M: Targeting the neurokinin-1 receptor compromises canonical wnt signaling in hepatoblastoma. Mol Cancer Ther 14(12): 2712-2721, 2015.

108 Alayev A and Holz MK: Mtor signaling for biological control and cancer. J Cell Physiol 228(8): 1658-1664, 2013.

109 Wagner F, Henningsen B, Lederer C, Eichenmüller M, Gödeke J, Müller-Höcker J, von Schweinitz D and Kappler R: Rapamycin blocks hepatoblastoma growth in vitro and in vivo implicating new treatment options in high-risk patients. Eur J Cancer 48(15): 2442-2450, 2012.

110 Garcia-Recio S, Fuster G, Fernandez-Nogueira P, Pastor-Arroyo EM, Park SY, Mayordomo C, Ametller E, Mancino M, Gonzalez-Farre X, Russnes HG, Engel P, Costamagna D, Fernandez PL, Gascon P and Almendro V: Substance $\mathrm{p}$ autocrine signaling contributes to persistent her 2 activation that drives malignant progression and drug resistance in breast cancer. Cancer Res 73(21): 6424-6434, 2013.

111 Garnier A, Vykoukal J, Hubertus J, Alt E, von Schweinitz D, Kappler R, Berger M and Ilmer M: Targeting the neurokinin-1 receptor inhibits growth of human colon cancer cells. Int $\mathrm{J}$ Oncol 47(1): 151-160, 2015.
112 Kovacina KS, Park GY, Bae SS, Guzzetta AW, Schaefer E, Birnbaum MJ and Roth RA: Identification of a proline-rich akt substrate as a 14-3-3 binding partner. J Biol Chem 278(12): 10189-10194, 2003.

113 Cross DA, Alessi DR, Cohen P, Andjelkovich M and Hemmings BA: Inhibition of glycogen synthase kinase- 3 by insulin mediated by protein kinase b. Nature 378(6559): 785-789, 1995.

114 Gingras AC, Gygi SP, Raught B, Polakiewicz RD, Abraham RT, Hoekstra MF, Aebersold R and Sonenberg N: Regulation of 4ebp1 phosphorylation: A novel two-step mechanism. Genes Dev 13(11): 1422-1437, 1999

115 Shuda M, Velasquez C, Cheng E, Cordek DG, Kwun HJ, Chang $\mathrm{Y}$ and Moore PS: Cdk1 substitutes for mtor kinase to activate mitotic cap-dependent protein translation. Proc Natl Acad Sci USA 112(19): 5875-5882, 2015.

116 Shang ZF, Yu L, Li B, Tu WZ, Wang Y, Liu XD, Guan H, Huang B, Rang WQ and Zhou PK: 4e-bp1 participates in maintaining spindle integrity and genomic stability via interacting with plk1. Cell Cycle 11(18): 3463-3471, 2012.

117 Copp J, Manning G and Hunter T: Torc-specific phosphorylation of mammalian target of rapamycin (mtor): Phospho-ser2481 is a marker for intact mtor signaling complex 2. Cancer Res 69(5): 1821-1827, 2009.

118 Sekulic A, Hudson CC, Homme JL, Yin P, Otterness DM, Karnitz LM and Abraham RT: A direct linkage between the phosphoinositide 3-kinase-akt signaling pathway and the mammalian target of rapamycin in mitogen-stimulated and transformed cells. Cancer Res 60(13): 3504-3513, 2000.

119 Treins C, Warne PH, Magnuson MA, Pende M and Downward $\mathrm{J}$ : Rictor is a novel target of p70 s6 kinase-1. Oncogene 29(7): 1003-1016, 2010.

120 Shah OJ, Wang $\mathrm{Z}$ and Hunter T: Inappropriate activation of the tsc/rheb/mtor/s6k cassette induces irs1/2 depletion, insulin resistance, and cell survival deficiencies. Curr Biol 14(18): 1650-1656, 2004.

121 Harrington LS, Findlay GM, Gray A, Tolkacheva T, Wigfield S, Rebholz H, Barnett J, Leslie NR, Cheng S, Shepherd PR, Gout I, Downes CP and Lamb RF: The tsc1-2 tumor suppressor controls insulin-pi3k signaling via regulation of irs proteins. $\mathrm{J}$ Cell Biol 166(2): 213-223, 2004.

122 Tzatsos A and Kandror KV: Nutrients suppress phosphatidylinositol 3-kinase/akt signaling via raptor-dependent mtor-mediated insulin receptor substrate 1 phosphorylation. Mol Cell Biol 26(1): 63-76, 2006

123 Julien LA, Carriere A, Moreau J and Roux PP: Mtorc1activated s6k1 phosphorylates rictor on threonine 1135 and regulates mtorc2 signaling. Mol Cell Biol 30(4): 908-921, 2010.

124 Breuleux M, Klopfenstein M, Stephan C, Doughty CA, Barys L, Maira SM, Kwiatkowski D and Lane HA: Increased akt s473 phosphorylation after mtorc1 inhibition is rictor dependent and does not predict tumor cell response to pi3k/mtor inhibition. Mol Cancer Ther 8(4): 742-753, 2009.

125 Chen KF, Chen HL, Tai WT, Feng WC, Hsu CH, Chen PJ and Cheng AL: Activation of phosphatidylinositol 3-kinase/akt signaling pathway mediates acquired resistance to sorafenib in hepatocellular carcinoma cells. J Pharmacol Exp Ther 337(1): 155-161, 2011.

126 Betz C and Hall MN: Where is mtor and what is it doing there? J Cell Biol 203(4): 563-574, 2013. 
127 Kim JE and Chen J: Cytoplasmic-nuclear shuttling of fkbp12rapamycin-associated protein is involved in rapamycin-sensitive signaling and translation initiation. Proc Natl Acad Sci USA 97(26): 14340-14345, 2000.

128 Bachmann RA, Kim JH, Wu AL, Park IH and Chen J: A nuclear transport signal in mammalian target of rapamycin is critical for its cytoplasmic signaling to s6 kinase 1. J Biol Chem 281(11): 7357-7363, 2006.

129 Martelli AM, Tabellini G, Bressanin D, Ognibene A, Goto K, Cocco L and Evangelisti C: The emerging multiple roles of nuclear akt. Biochim Biophys Acta 1823(12): 2168-2178, 2012.

130 Wan X, Harkavy B, Shen N, Grohar P and Helman LJ: Rapamycin induces feedback activation of akt signaling through an igf-1rdependent mechanism. Oncogene 26(13): 1932-1940, 2007.

131 Lickert H, Bauer A, Kemler R and Stappert J: Casein kinase ii phosphorylation of e-cadherin increases e-cadherin/beta-catenin interaction and strengthens cell-cell adhesion. J Biol Chem 275(7): 5090-5095, 2000.

132 McCubrey JA, Steelman LS, Bertrand FE, Davis NM, Sokolosky M, Abrams SL, Montalto G, D'Assoro AB, Libra M, Nicoletti F, Maestro R, Basecke J, Rakus D, Gizak A, Demidenko ZN, Cocco L, Martelli AM and Cervello M: Gsk-3 as potential target for therapeutic intervention in cancer. Oncotarget 5(10): 2881-2911, 2014.

133 Lilien J and Balsamo J: The regulation of cadherin-mediated adhesion by tyrosine phosphorylation/ dephosphorylation of beta-catenin. Curr Opin Cell Biol 17(5): 459-465, 2005.

134 Zhang N, Wei P, Gong A, Chiu WT, Lee HT, Colman H, Huang H, Xue J, Liu M, Wang Y, Sawaya R, Xie K, Yung WK, Medema RH, He X and Huang S: Foxm1 promotes beta-catenin nuclear localization and controls wnt target-gene expression and glioma tumorigenesis. Cancer Cell 20(4): 427-442, 2011.

135 Scheel C and Weinberg RA: Cancer stem cells and epithelialmesenchymal transition: Concepts and molecular links. Semin Cancer Biol 22(5-6): 396-403, 2012.

136 Larue L and Bellacosa A: Epithelial-mesenchymal transition in development and cancer: Role of phosphatidylinositol 3' kinase/akt pathways. Oncogene 24(50): 7443-7454, 2005.

137 Heuberger J and Birchmeier W: Interplay of cadherin-mediated cell adhesion and canonical wnt signaling. Cold Spring Harb Perspect Biol 2(2): a002915, 2010.

138 Lamouille S, Xu J and Derynck R: Molecular mechanisms of epithelial-mesenchymal transition. Nat Rev Mol Cell Biol 15(3): 178-196, 2014.

139 Hulkower KI and Herber RL: Cell migration and invasion assays as tools for drug discovery. Pharmaceutics 3(1): 107-124, 2011.

140 Yoshida Y, Wang IC, Yoder HM, Davidson NO and Costa RH: The forkhead box $\mathrm{m} 1$ transcription factor contributes to the development and growth of mouse colorectal cancer. Gastroenterology 132(4): 1420-1431, 2007.

141 Chen Y, Li Y, Xue J, Gong A, Yu G, Zhou A, Lin K, Zhang S, Zhang N, Gottardi CJ and Huang S: Wnt-induced deubiquitination foxm1 ensures nucleus beta-catenin transactivation. EMBO J 35(6): 668-684, 2016.

142 Inoki K, Ouyang H, Zhu T, Lindvall C, Wang Y, Zhang X, Yang Q, Bennett C, Harada Y, Stankunas K, Wang CY, He X, MacDougald OA, You M, Williams BO and Guan KL: Tsc2 integrates wnt and energy signals via a coordinated phosphorylation by ampk and gsk3 to regulate cell growth. Cell 126(5): 955-968, 2006.
143 Bowman CJ, Ayer DE and Dynlacht BD: Foxk proteins repress the initiation of starvation-induced atrophy and autophagy programs. Nat Cell Biol 16(12): 1202-1214, 2014.

144 Partridge L and Bruning JC: Forkhead transcription factors and ageing. Oncogene 27(16): 2351-2363, 2008.

145 Gao C, Cao W, Bao L, Zuo W, Xie G, Cai T, Fu W, Zhang J, Wu W, Zhang $X$ and Chen YG: Autophagy negatively regulates wnt signalling by promoting dishevelled degradation. Nat Cell Biol 12(8): 781-790, 2010.

146 Jung CH, Ro SH, Cao J, Otto NM and Kim DH: Mtor regulation of autophagy. FEBS Lett 584(7): 1287-1295, 2010.

147 Noda T and Ohsumi Y: Tor, a phosphatidylinositol kinase homologue, controls autophagy in yeast. J Biol Chem 273(7): 3963-3966, 1998.

148 Reya $\mathrm{T}$ and Clevers H: Wnt signalling in stem cells and cancer. Nature 434(7035): 843-850, 2005.

149 Vermeulen L, De Sousa EMF, van der Heijden M, Cameron K, de Jong JH, Borovski T, Tuynman JB, Todaro M, Merz C, Rodermond H, Sprick MR, Kemper K, Richel DJ, Stassi G and Medema JP: Wnt activity defines colon cancer stem cells and is regulated by the microenvironment. Nat Cell Biol 12(5): 468476, 2010.

150 Ilmer M, Boiles AR, Regel I, Yokoi K, Michalski CW, Wistuba, II, Rodriguez J, Alt E and Vykoukal J: Rspo2 enhances canonical wnt signaling to confer stemness-associated traits to susceptible pancreatic cancer cells. Cancer Res 75(9): 1883-1896, 2015.

$151 \mathrm{Yu}$ Y, Ramena G and Elble RC: The role of cancer stem cells in relapse of solid tumors. Front Biosci (Elite Ed) 4: 1528-1541, 2012.

152 Esteban F, Munoz M, Gonzalez-Moles MA and Rosso M: A role for substance $\mathrm{p}$ in cancer promotion and progression: A mechanism to counteract intracellular death signals following oncogene activation or DNA damage. Cancer Metastasis Rev 25(1): 137-145, 2006.

153 Castro TA, Cohen MC and Rameshwar P: The expression of neurokinin-1 and preprotachykinin-1 in breast cancer cells depends on the relative degree of invasive and metastatic potential. Clin Exp Metastasis 22(8): 621-628, 2005.

154 Misawa K, Kanazawa T, Misawa Y, Imai A, Uehara T, Mochizuki D, Endo S, Takahashi G and Mineta H: Frequent promoter hypermethylation of tachykinin-1 and tachykinin receptor type 1 is a potential biomarker for head and neck cancer. J Cancer Res Clin Oncol 139(5): 879-889, 2013.

155 Garnier A, Ilmer M, Becker K, Häberle B, von Schweinitz D, Kappler R and Berger M: Truncated neurokinin-1 receptor is an ubiquitous antitumor target in hepatoblastoma, and its expression is independent of tumor biology and stage. Oncology Letters 11: 2015.

156 Cairo S, Armengol C and Buendia MA: Activation of wnt and myc signaling in hepatoblastoma. Front Biosci (Elite Ed) 4: 480486, 2012.

157 Munoz M and Covenas R: Neurokinin-1 receptor: A new promising target in the treatment of cancer. Discov Med 10(53): 305-313, 2010. 